\title{
ĐÁNH GIÁ SỚM KẾT QUẢ ĐIỀU TRI BỆNH VIÊM TẮC ĐỘNG MẠCH MẠN TÍNH HAI CHI DƯỚI BẦNG CẦU NỐI NGOÀI GIẢI PHẪU
}

Lê Quang Thúu *

\section{TÓM TẮT}

Đối tượng và phương pháp nghiên cứu: Từ 01/2009 đến 12/2011 nghiên cứu tiển cứu tại khoa ngoại Lồng Ngực - Tim Mạch BV TW Huế đã có 64 bệnh nhân vào viện điều trị bệnh viêm tắc động mạch mạn tinh 2 chi dưới bằng cầu nối ngoài giải phẫu, trong đó có 52 nam, 12 nữ với độ tuổi từ 32 đến 91 tuồi.

Mục tiêu nghiên cứu: Đánh giá kết quả 6-12 tháng sau phẫu thuật làm cầu nối ngoài giải phẫu.

Kết quả: Đa số các bệnh nhân khi nhập viện đều trong tình trạng nặng nề của bệnh, chủ yếu là giai đoạn III, IV theo phân độ của Leriche-Fonrtaine, với giai đoạn IV chiếm $87,5 \%$. Tất cả các bệnh nhân nhập viện đều được làm siêu âm Doppler động mạch và chụp động mạch chân bị viêm tắc, kết quả tắc nghẽn chủ yếu ở động mạch đùi nông $(81,25 \%)$. Sau đó, chúng tôi chỉ định làm cầu nối ngoài giải phẫu, cao nhất là cầu nối đùi - khoeo $(62,5 \%)$, cẩu nối đùi - chày sau $(25 \%)$, tiếp đến là cầu nối đùi chày trước và khoeo - mác $(6,25 \%)$.

Theo dõi 6-12 tháng sau khi làm cầu nối ngoài giải phẫu, chúng tôi nhận thấy tỷ lệ cầu nối thông tốt lên đến $81,25 \%$, tắc cầu nối $18,75 \%$. Biến chứng sau mổ: chảy máu sau mổ $12,5 \%$, nhiễm trùng vết mổ $12,5 \%$, và biến chứng cắt cụt đoạn chi sau phẫu thuật làm cầu nối $6,25 \%$.

Abstract

Subjects and methods: From 01/2009 to 12/2011, prospective study at Department of Thoracic and Cardiovascular Surgery of Hue Centre hospital, we have performed 64 patients in 52 males and 12 females from 32 to 91 ages, who were treated chronic occlusive arterial disease of lower extremity by bypass.

Objectives: Evaluate of early results in 6-12 months postoperatively.

Results: Majority of patients suffered from pains at rest or ischemic ulcers and necrosis, the stage of disease was stage IV (87.5\%) according to Leriche Fontaine. All patients underwent Echo Doppler and angiography the leg which was obstructed and the major obstructive result in superficial femoral artery in $81.25 \%$. And then we defined to do bypass surgery in which highest rate is femoral - popliteal artery bypass $(62.5 \%)$, femoral - posterial tibial artery bypass surgery in $25 \%$, femoral - anterial tibial artery and popliteal - calf artery bypass surgery in $6.25 \%$. During 6-12 postoperative months following up, the rate of graft failed was $18.75 \%$. Complications of postoperative included hemorrhage in $12.5 \%$, wound infection in $12.5 \%$ and severe complication was amputation after bypass surgery in $6.25 \%$.

Conclusion: Most of the patients come to hospital was men at stage IV (ulcer, necrosis). So, the indication of bypass surgery was still limit. However, result of early bypass surgery has shown a good effect relatively.

\section{I. ĐĂT VẤN ĐỀ}

Bệnh viêm tắc động mạch mạn tính hai chi dưới thường là do hậu quả hẹp dần dần các động mạch tưới máu đến hai chi (chậu, đùi, khoeo, các động mạch cẳng chân). Bệnh thường gặp ở nam giới, có thể không có triệu chứng và phát hiện duy nhất là mất mạch ngoại biên, hay có biểu hiện lâm sàng (dị cảm chi, đi lặc cách hồi, loạn dưỡng...) và thường xuất hiện sau 60 tuổi [9], chính vì vậy việc chẩn đoán viêm tắc động mạch mạn tính hai chi dưới tương đối dễ dàng do các triệu chứng đặc hiệu của bệnh.

Trong những năm gần đây, nhờ sự phát triển của các kỹ thuật thăm dò hình ảnh, chức năng (đặc biệt là siêu âm Doppler, chụp động mạch, CT 64 lát cắt), song song với sự tiến bộ trong kỹ thuật - trang thiết bị mổ, sự nâng cao trình độ tay nghề của các bác sĩ phẫu thuật đặc biệt trong lĩnh vực tim mạch - lồng ngực, tại Bệnh Viện Trung Ương Huế đã tiến hành chẩn đoán và điều trị phẫu thuật cho các trường hợp VTĐMMT hai chi dưới bằng cầu nối ngoài giải phẫu.

\section{MỤC TIÊU NGHIÊN CỨU}

Đánh giá sớm kết quả điều trị bệnh VTĐMMT hai chi dưới bằng cầu nối ngoài giải phẫu (6-12 tháng sau phẫu thuật)

\section{II. ĐỐI TƯợ̂ VÀ PHƯƠNG PHÁP NGHIÊN CÚU}

Chúng tôi ghi nhận số liệu các bệnh nhân nhập viện điều trị tại khoa Ngoại Tim Mạch - Lồng Ngực BV Trung Ương Huế và được chẩn đoán, điều trị phẫu thuật VTĐMMT hai chi dưới bằng cầu nối ngoài giải phẫu từ tháng $01 / 2009$ đến $12 / 2011$. Tồng số 64 bệnh nhân, được ghi lại thông tin cá nhân, thời điểm nhập viện, dấu hiệu lâm sàng, kết quả cận lâm sàng, phương pháp điều trị ngoại khoa, và ghi nhận kết quả 6-12 tháng sau phẫu thuật.

\footnotetext{
* Truòng Đại hoc Y Dươc Hué
} 


\section{KẾT QUẢ}

\section{Bảng 1: Giới}

\begin{tabular}{lll}
\hline Giới & $\mathbf{N}$ & \% \\
\hline Nam & 52 & 82,25 \\
Nữ & 12 & 18,75 \\
Tổng & 64 & 100 \\
\hline
\end{tabular}

\section{Bảng 2: Phân độ theo Leriche - Fonrtaine}

\begin{tabular}{lll}
\hline Phân độ & $\mathbf{N}$ & \% \\
\hline Độ III & 8 & 12,5 \\
Độ̉ IV & 56 & 87,5 \\
Tồng & 64 & 100 \\
\hline
\end{tabular}

Bảng 3: Bệnh phối hợp

\begin{tabular}{lll}
\hline Bệnh & N & \% \\
\hline THA & 24 & 37,5 \\
ĐTĐ & 4 & 6,25 \\
Thalassemia & 4 & 6,25 \\
Tồng & 32 & \\
\hline
\end{tabular}

Bảng 4: Siêu âm Doppler mạch

\begin{tabular}{lll}
\hline Kết quả & $\mathbf{N}$ & $\mathbf{\%}$ \\
\hline Hẹp/tắc động mạch đùi nông & 42 & 81,25 \\
Tắc động mạch khoeo & 12 & 18,75 \\
Tổng & 64 & 100 \\
\hline
\end{tabular}

Trong 64 bệnh nhân nhập viên chỉ có 56 bệnh nhân được chỉ định chụp mạch, 4 bệnh nhân được chụp CTScan 64 lát cắt, và 4 bệnh nhân do bị suy thận nên chống chỉ định chụp mạch, chúng tôi chỉ căn cứ vào kết quả siêu âm để phẫu thuật. 4 bệnh nhân chụp CTScan với kết quả tắc 2/3 trên động mạch đùi nông.

\section{Bảng 5: Kết quả chụp mạch}

\begin{tabular}{lll}
\hline Động mạch bị hẹp/tắc & N & \% \\
\hline Đùi nông & 42 & 92,85 \\
Đùi sâu & 12 & 21,42 \\
Khoeo & 20 & 35,71 \\
Chày trước & 24 & 42,85 \\
Chày sau & 28 & 50 \\
Mác & 20 & 35,71 \\
\hline
\end{tabular}


Bảng 6: Cầu nối ngoài giải phẫu

\begin{tabular}{lll}
\hline Cầu nối & $\mathbf{N}$ & \% \\
\hline Đùi-Khoeo & 40 & 62,5 \\
Đùi-Chày sau & 16 & 25 \\
Đùi-Chày trước & 4 & 6,25 \\
Khoeo-Mác & 4 & 6,25 \\
Tổng & 64 & 100 \\
\hline
\end{tabular}

\section{Bảng 7: Kết quả và biến chứng}

\begin{tabular}{lll}
\hline Kết quả/Biến chứng & $\mathbf{N}$ & $\mathbf{\%}$ \\
\hline Cầu nối thông tốt & 52 & 81,25 \\
Tắc cầu nối & 12 & 18,75 \\
Chảy máu sau mổ & 8 & 12,5 \\
Nhiểm trùng vết mổ & 8 & 12,5 \\
Cắt cụt chi & 4 & 6,25 \\
Tử vong & 0 & 0 \\
\hline
\end{tabular}

Bảng 8: Mổ lại sau phẫu thuật làm cầu nối

\begin{tabular}{lll}
\hline Số lần mổ lại & $\mathbf{N}$ & $\%$ \\
\hline 1 lần & 4 & 6,25 \\
2 lần & 8 & 12,5 \\
Tổng & 12 & 18,75 \\
\hline
\end{tabular}

\section{BÀN LUẬN}

CHİ ĐỊNH PHẪU THUẬT: Phẫu thuật bắc cầu là một trong các kỹ thuật ngoại khoa điều trị tắc hẹp mạch, nhằm đưa máu từ trền xuống dưới chỗ tắc mà không nhất thiết phải tác động trực tiếp vào đoạn mạch bệnh lý.

Tất cả 64 bệnh nhân được làm siêu âm Doppler mạch và chụp động mạch hay chụp CTScan 64 nhát cắt cho thấy động mạch khoeo còn thông và hoặc còn ít nhất 1 trong 3 trục động mạch chính cẳng chân (ĐM chày trước, ĐM chày sau, ĐM mác), đủ điều kiện để làm phẫu thuật cầu nối ngoài giải phẫu. Trong nghiên cứu của chúng tôi, tỷ lệ hẹp/tắc ĐM đùi nông cao nhất $81,25 \%$, ĐM khoeo bị tắc hoàn toàn chiếm $18,75 \%$.

Đường mổ phụ thuộc vào vị trí của ĐM cho, $\mathrm{ĐM}$ nhận, và đường đi của cầu nối mà chúng tôi lựa chọn những đường mổ khác nhau. Tuy nhiên, trong nghiên cứu của chúng tôi, đường mổ ở vùng Scarpa có 60 trường hợp, do chúng tôi lựa chọn ĐM cho là ĐM đùi, và đường mổ bên trong đùi-khoeo-cẳng chân (đường đi của cầu nối). ĐM cho cần được kiểm tra trước mổ (siêu âm Doppler) và trong mổ cần đảm bảo phải còn mềm mại, đập tốt. Theo nghiên cứu của Michael Conte [1], ĐM cho là ĐM đùi chung: 49\%, ĐM đùi nông: $25 \%$, ĐM khoeo: 18\%. Theo Đoàn Quốc Hưng [5], tác giả thường lấy ĐM đùi nông và ĐM khoeo làm ĐM cho vì hai lý do:

+ Cho rằng cầu nối càng ngắn càng tốt.

+ Không phải lúc nào cũng có đoạn ghép $\mathrm{TM}$ đủ dài $(75-90 \mathrm{~cm})$ để nối cao lên đến ĐM chậu ngoài, ĐM đùi chung.

Liên quan đến ĐM nhận, vấn đề đánh giá trong mổ là rất quan trọng để quyết định khả năng tái lập tuần hoàn hay không, yêu cầu $\mathrm{ĐM}$ còn mềm mại có lòng thông được là chúng tôi có thể làm miệng nối. Trong nghiên cứu của chúng tôi, ĐM nhận là ĐM khoeo chiếm : $62.5 \%$, ĐM chày sau: $25 \%$, ĐM chày trước: $6.25 \%$, ĐM mác: $6.25 \%$. Theo Michael Conte [1], ĐM nhận chủ yếu là ĐM chày sau: $53 \%$, ĐM khoeo: $33 \%$, ĐM bàn chân: $12 \%$. Theo Đoàn Quốc Hưng [5], mạch nhận là một trong ba trục mạch cẳng chân: $57 \%$. 
KỸ THUẬT: Khi đã kiểm tra và quyết định làm cầu nối, chúng tôi lựa chọn $\mathrm{TM}$ hiển trong để làm cầu nối chiếm $100 \%$. Đoạn TM sau khi được rửa sạch, thắt các nhánh bên, dùng một kim đầu tù luồng vào trong lòng bơm căng để kiểm tra xem có xì dò không. Tiếp đến chúng tôi làm miệng nối tận bên với $\mathrm{OM}$ cho (thường dùng chỉ Prolene 6.0) khâu vắt, làm đầy đoạn ghép, luồn TM theo đường mổ lấy TM hiển tránh bị vặn xoắn, gập góc. Cẳng chân lúc này phải duỗi ra để ước lượng đoạn $\mathrm{TM}$ đủ dài, tránh làm căng miệng nối. Sau đó, chúng tôi tiếp tục làm miệng nối tận bên với ĐM nhận. Cầm máu kĩ và dẫn lưu tốt để tránh gây ứ đọng dịch hay chảy máu sau mổ, v́ sau mổ có sử dụng Heparin nên dễ xảy ra chảy máu nếu không cầm máu kĩ.

Trong thời gian hậu phẫu, để đánh giá kết quả của cầu nối, chúng tôi thường dùng siêu âm Doppler để kiểm tra. Có 3 nguyên nhân cơ bản khiến cho cầu nối bị thất bại: huyết khối, rối loạn huyết động, cấu trúc cầu nối không phù hợp. Tùy thuộc vào thời gian hậu phẫu mà có thêm các nguyên nhân khác: Cầu nối thất bại trong giai đoạn sớm ( $<30$ ngày) thường là do sai kỹ thuật, nhiễm trùng, hoặc bệnh nhân trong tình trạng tăng đông máu. Từ 1 tháng -2 năm, nguyên nhân do chính bản thân của cầu nối, mạch cho, mạch nhận. Trên 2 năm, nguyên nhân thường do sự tiến triển của bệnh xơ vữa động mạch [7].

KÊT QUẢ: Trong 64 trường hợp, cầu nối đùi khoeo chiếm $62.5 \%$, đùi - chày sau $25 \%$, ít nhất là cầu nối đùi - chày trước và cầu nối khoeo - mác $6.25 \%$, phù hợp với kết quả nghiên cứu của Đoàn Quốc Hưng [5] với cầu nối đùi khoeo: $38.09 \%$, đùi chày sau: $19.04 \%$, đùi - chày trước $9.52 \%$, khoeo mác $4.76 \%$ và John Hoch [8] với cầu nối đùi-khoeo: $45 \%$, đùi-chày: $20 \%$, khoeo-chày: $20 \%$. Trong kết quả của chúng tôi, kiểm tra cầu nối bằng siêu âm Doppler sau mổ cho kết quả cầu nối thông tốt: $81.25 \%$. Tuy vậy, vẫn còn $18.75 \%$ tắc cầu nối sớm sau mổ, cao hơn so với nghiên cứu của Michael [1] là $5.2 \%$, Dennis Joseph [4] tỷ lệ tắc cầu nối sớm là 2 $-3 \%$, còn trong lô nghiên cứu của Davidson [3] là $4,2 \%$, và tỷ lệ tắc cầu nối sớm của các tác giả nước ngoài khác như Niten Singh và cs: 4,9\% [12], Omaida Velazquez: 12\% [13], Jacob Robinson nghiên cứu trên 54 bệnh nhân thì có 8 bệnh nhân bị tắc cầu nối sớm [10], nghiên cứu của Carlos Crus, tỷ lệ tắc cầu nối sớm khiến bệnh nhân phải cắt cụt dưới gối, trên gối lần lượt là $15 \%$ và $7 \%$ [2]. Giải thích cho kết quả này có thể do lỗi kỹ thuật gây hẹp miệng nối hay có thể do chưa đánh giá hết được các thương tổn bên dưới chỗ tắc. Trong những trường hợp tắc cầu nối, chúng tôi tiến hành điều trị nội khoa có đáp ứng lâm sàng là 8 trường hợp (cải thiện rõ triệu chứng: đỡ đau, chân ấm). Trong nghiên cứu của Jacob Robinson trong 54 trường hợp thì có 3 trường hợp có dòng chảy qua cầu nối $<45 \mathrm{~cm} /$ giây nguy cơ bị tắc, 1 bệnh nhân bị tắc cầu nối nhưng điều trị nội khoa ổn định mà không cần phải cắt cụt [10]. Còn 4 trường hợp $(6,25 \%)$ chúng tôi phải tiến hành cắt cụt $1 / 3$ trên cẳng chân, mặc dù vậy diện cắt của mỏm cụt vẫn tiếp tục hoại tử nên chúng tôi phải tiến hành cắt lên $1 / 3$ dưới đùi. Theo Joe Feinglass và $\mathrm{cs}$, tỷ lệ cắt cụt 2,6\% [6] thấp hơn so với nghiên cứu của chúng tôi, điều này thiết nghĩ do bệnh nhân của chúng tôi nhập viện điều trị trong giai đoạn muộn, chủ yểu là giai đoạn $\mathrm{IV}$, nên khả năng cắt cụt cao hơn so với nghiên cứu của tác giả trên.

Có 8 trường hợp chảy máu và tụ máu sau mổ $(12,5 \%)$, chúng tôi phải tiến hành mổ lại để cầm máu và lấy khối máu tụ. Nhiễm trùng vết mổ sau phẫu thuật có 8 trường hợp $(12,5 \%)$ cao hơn so với nghiên cứu của các tác giả nước ngoài. Nguyên nhân có thể do môi trường hậu phẫu của chúng tôi dễ gây nhiễm trùng hơn và tỷ lệ vi khuẩn kháng thuốc cao hơn so với tác giả khác.

Trong nghiên cứu của chúng tôi, không có trường hợp nào tử vong. Tuy nhiên theo nhiều tác giả nước ngoài, tỷ lệ tử vong theo Jessica Simons: 2,2\% [11], theo Joe Feinglass: 4,3\% [6], theo Niten Singh và cs: 230/14.788 trường hợp tử vong [12].

\section{KẾT LUẬN}

Qua 64 trường hợp VTĐMMT 2 chi dưới đã được làm cầu nối động mạch bằng tĩnh mạch hiển đảo ngược ở BVTW Huế cho thấy đây là một phương pháp điều trị cho kết quả tương đối khả quan, bảo tồn được chi bị bệnh (60 trường hợp), chỉ có 4 trường hợp phải cắt cụt. Phương pháp này được chỉ định cho những bệnh nhân ĐM còn mềm mại, tuần hoàn bên dưới chỗ tắc còn tốt, chính vì vậy, cần phải khuyến cáo bệnh nhân nhận biết sớm các triệu chứng của bệnh cũng như các yếu tố nguy cơ để phòng ngừa nhằm nâng cao hiệu quả điều trị.

\section{TÀI LIỆU THAM KHẢO}

1. Conte Michael S. et al (2003), "Results of prevent III: A multicenter,randomized trial of edifoligide for the prevent of vein graft failure in lower extremity bypass surgery". J Vasc Surg 2006; 43: 742-751.

2. Cruz Carlos P. et al (2003), "Major lower extremity amputations at a Veterans Affairs hospital ". The American of surgery 186 (2003): 449 - 454. 
3. Davidson JT 3rd, Callis JT-Arterial reconstruction of vessels in the foot and ankle-Ann Surg, 1993 June.

4. Dennis Joseph M, Surgical Management of Femoral Popliteal Occlusive Diseases: Surgical and Interventional Therapy.

5. Đoàn Quốc Hưng, Nguyễn Hữu Ước, Nguyễn Văn Mão, Lê Ngọc Thành, Hoàng Việt Dũng, Đặng Hanh Đệ (2000), "Sử dụng tĩnh mạch hiển tự thân trong điều trị ngoại khoa thiếu máu nặng chi dưới mạng tính”. Ngoại khoa số 5/2000: 19-25.

6. Feinglass Joe et al (2009), "Perioperative outcomes and amputation-free survival after lower extremity bypass surgery in California hospitals, 1996-1999, with follow-up through 2004". J Vasc Surg 2009;50: 776-783.

7. Foldes S. (1994), "Postoperative lower extremity bypass surveillance: Beyond ankle arm blood pressures". J Vasc Surg 1995;13: 75-78.

8. Hoch John R. et al (1999), "Comparison of treatment plans for lower extremity arterial occlusive disease made with electrocardiography-triggered two dimensional time of flight magnetic resonance angiography and digital subtraction angiography". Am J Surg 1999;178: 166-173.

9. Nguyễn Lương Kỷ, Lê Thị Hải Yến (2001), "Nghiên cứu lâm sàng, cận lâm sàng và yếu tố nguy cơ bệnh lý viêm tắc động mạch mạn tính”, Luận văn tốt nghiệp bác sĩ y khoa, Đại học Y khoa Huế.

10. Robinson Jacob G. et al (1990), "Does postoperative surveillance with duplex scanning identify the failing distal bypass". Ann Vasc Surg 1991:5: 182-185.

11. Simons Jessica P. et al (2010), "Failure to achieve clinical improvement despite graft patency in patients undergoing infrainguinal lower extremity bypass for critical limb ischemia". The society for clinical vascular surgery 2010: 1419-1424.

12. Singh Niten et al (2006), "The effects of the type of anesthesia on outcome of lower extremity infrainguinal bypass". J Vasc Surg 2006;44: 964970.

13. Velazquez Omaida C. et al (1998), "Magnetic resonance angiography of lower extremity arterial disease". Surgical clinics of North America 1998: 519-538. 